\title{
Genetic, Geographic, and Environmental Correlates of Human Temporal Bone Variation
}

\author{
Heather F. Smith, ${ }^{1{ }^{* \dagger}}$ Claire E. Terhune, ${ }^{1{ }^{* \dagger}}$ and Charles A. Lockwood ${ }^{2}$ \\ ${ }^{1}$ School of Human Evolution and Social Change, Arizona State University, Tempe, AZ 85287-2402 \\ ${ }^{2}$ Department of Anthropology, University College London, London WC1E 6BT, UK
}

KEY WORDS geometric morphometrics; molecular distance; cranial morphology

\begin{abstract}
Temporal bone shape has been shown to reflect molecular phylogenetic relationships among hominoids and offers significant morphological detail for distinguishing taxa. Although it is generally accepted that temporal bone shape, like other aspects of morphology, has an underlying genetic component, the relative influence of genetic and environmental factors is unclear. To determine the impact of genetic differentiation and environmental variation on temporal bone morphology, we used threedimensional geometric morphometric techniques to evaluate temporal bone variation in 11 modern human populations. Population differences were investigated by discriminant function analysis, and the strength of the relationships between morphology, neutral molecular distance, geographic distribution, and environmental variables were assessed by matrix correlation comparisons. Significant differences were found in temporal bone shape among all populations, and classification rates using cross-validation
\end{abstract}

Like other aspects of phenotype, cranial morphology reflects a combination of genetic and environmental influences (Moss, 1962, 1972). Within this framework, some authors have suggested that particular portions of the cranium may be less prone to variation due to environmental variables, and therefore more phylogenetically informative (Olson, 1981; Strait et al., 1997; Lieberman et al., 2000a; Harvati, 2001; Wood and Lieberman, 2001; Harvati and Weaver, 2006a,b). For hominins, traits associated with heavy chewing have been argued to be homoplastic and consequently unreliable indicators of phylogeny (Walker et al., 1986; Wood, 1988; Skelton and McHenry, 1992; Turner and Wood, 1993; McHenry, 1994, 1996; Lieberman et al., 1996; but see Strait et al., 1997; Asfaw et al., 1999; Collard and Wood, 2001). The morphology of the cranial base has especially been regarded as a reliable reflection of genetic relationships, as it forms very early during ontogeny and ossifies endochondrally (Moore and Lavelle, 1974; Olson, 1981; MacPhee and Cartmill, 1986; Lieberman et al., 2000a,b). The cranial base also mirrors the shape of the developing brain, which is relatively constrained (Houghton, 1996). Basicranial characters may therefore be less influenced by epigenetic forces than are the externally sensitive intramembraneous bones of the facial skeleton.

The morphology of the temporal bone, as part of the cranial base, may also reflect neutral molecular distances within species and phylogenetic relationships among species. However, the temporal bone also serves a variety of functional roles, such as posture, hearing, balance, mastication, and formation of the braincase. Consequently, this element can serve as a test case of the were relatively high. Comparisons of morphological distances to molecular distances based on short tandem repeats (STRs) revealed a significant correlation between temporal bone shape and neutral molecular distance among Old World populations, but not when Native Americans were included. Further analyses suggested a similar pattern for morphological variation and geographic distribution. No significant correlations were found between temporal bone shape and environmental variables: temperature, annual rainfall, latitude, or altitude. Significant correlations were found between temporal bone size and both temperature and latitude, presumably reflecting Bergmann's rule. Thus, temporal bone morphology appears to partially follow an isolation by distance model of evolution among human populations, although levels of correlation show that a substantial component of variation is unexplained by factors considered here. Am J Phys Anthropol 134:312-322, 2007. @2007 Wiley-Liss, Inc.

ways in which cranial morphology covaries with molecular distances and environmental factors and a test of the hypothesis that cranial base elements have a strong genetic component.

Several recent studies of variation in the temporal bone have demonstrated this region's utility in distinguishing among species and subspecies of extant great apes, and for quantifying levels of variation within and between taxa (Harvati, 2001, 2003; Lockwood et al., 2002, 2004, 2005; Terhune et al., 2007). In particular, Lockwood et al. (2004) demonstrated that, using shape distributions of coordinate data from modern humans, orangutans, gorillas, chimpanzees, and bonobos, the resultant phylogenetic tree of these taxa was identical to the molecular phylogeny of these species. Similarly, sev-

\footnotetext{
Grant sponsors: AMNH Collections Study Grant and ASU Department of Anthropology; Grant number: NSF BCS-9982022.

*Correspondence to: Heather F. Smith or Claire E. Terhune, School of Human Evolution and Social Change, Arizona State University, Box 872402, Tempe, AZ 85287-2402, USA.

E-mail: heather.f.smith@asu.edu or claire.terhune@asu.edu
}

${ }^{\dagger}$ These authors contributed equally to this work.

Received 12 December 2006; accepted 8 May 2007

DOI 10.1002/ajpa.20671

Published online 13 July 2007 in Wiley InterScience (www.interscience.wiley.com). 
Fig. 1. Map of the world showing the approximate locations of populations used in the morphological analysis (triangles), populations used in the molecular analysis (circles), and waypoints (squares). Lines link the morphological populations and their genetic representatives.

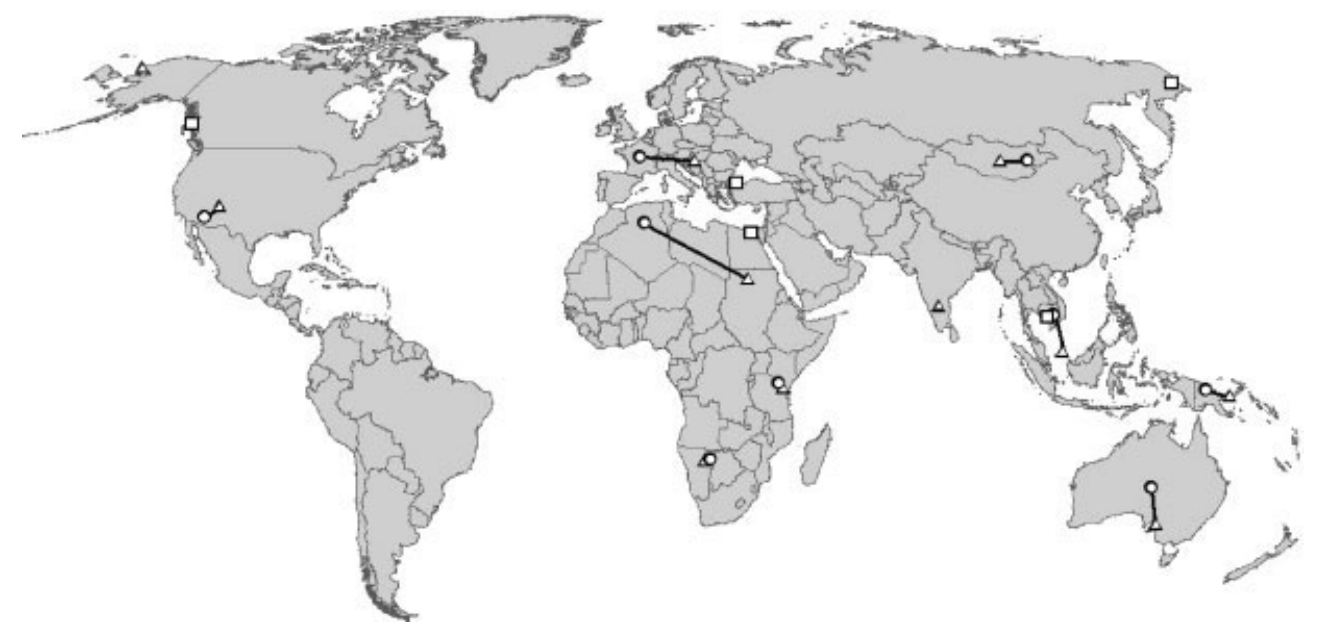

eral recent studies (Harvati, 2001, 2003; Terhune et al., 2007) have used the morphology of the temporal bone to test hypothesized taxonomic divisions among fossil taxa.

Given this background, we sought to investigate the association between temporal bone morphology and molecular distance among human populations, together with geographic distance and external factors such as environmental variables. Some recent studies have explicitly evaluated these influences on cranial anatomy (Relethford, 1994, 1998, 2001, 2002; Gonzales-Jose et al., 2004; Roseman, 2004). Linear dimensions of the skull have been shown to reflect genetic relationships of human populations, such that closely related populations tend to be more similar in overall cranial form (Relethford, 2001, 2002; Gonzales-Jose et al., 2004; Roseman, 2004). However, selective pressures acting on the skull of certain human populations have also been identified and can have a significant impact on cranial morphology of populations living in regions with extreme temperatures, such as Siberia (Roseman, 2004). Diversifying regional selection due to climate also affects the cranial morphology of several other human populations (Carey and Steegmann, 1981; Franciscus and Long, 1991; Roseman, 2004).

Harvati and Weaver (2006a,b) analyzed the correlation between human morphological variation in three cranial regions - the temporal bone, cranial vault, and facial skeleton - with molecular distances and environmental variables. They concluded that the morphology of the temporal bone and cranial vault are correlated with molecular distance in human populations, while facial morphology covaries more reliably with environment. The correlation between temporal bone shape and molecular distance was significant but low, suggesting that other factors also play a significant role in patterns of temporal bone morphology in humans. In addition, temporal bone centroid size was found to be correlated with temperature, a finding that is consistent with environmental variation in body size as first outlined by Bergmann (1847).

Our goal is to use an independent dataset and an expanded set of landmarks on the temporal bone to replicate part of the study of Harvati and Weaver (2006a). We also include additional environmental variables such as rainfall and altitude, and explore the relationship between morphology and geographic distance.

In general, we are testing the hypothesis that the temporal bone follows an isolation by distance model of evo- lution in human populations (Wright, 1943). More specifically, three research questions were investigated:

Q1. Are modern human populations significantly different in temporal bone morphology?

Q2. What is the strength of the correlation between temporal bone morphology and molecular distance among populations of modern humans?

Q3. How do external variables such as environmental differences or geographic distance covary with patterns of temporal bone morphology in humans?

\section{MATERIALS AND METHODS Data collection}

A total of 243 individuals from 11 modern human populations were included in this study (Fig. 1, Table 1). Specimens were housed at the American Museum of Natural History and Arizona State University. Individuals with extensive antemortem tooth loss were generally avoided to minimize the possibility of alveolar resorption affecting the morphology of the temporomandibular joint (TMJ). Following Lockwood et al. (2002), 22 landmarks from the ectocranial surface of the temporal bone were employed, which describe the morphology of the mandibular fossa, tympanic, mastoid, and petrous portions of the temporal bone (Fig. 2, Table 2). In comparison, Harvati and Weaver (2006a) used 13 landmarks.

An Immersion Microscribe point digitizer was used to record the three-dimensional coordinates of each landmark. These three-dimensional data were then analyzed using Morphologika (O'Higgins and Jones, 1998). First, three-dimensional coordinate data were registered through a generalized Procrustes analysis (GPA) (Gower, 1975; Goodall, 1991; Dryden and Mardia, 1998). Subsequently, variation in shape was investigated through principal components analysis (PCA). Output from these analyses (Procrustes residuals from the GPA and PC scores from the PCA) was recorded and copied into other statistical programs for further analysis. All threedimensional data were collected by the second author, and intraobserver error for a subset of the data set used here is reported by Terhune et al. (2007).

Data on 783 STRs in matched analogues of nine of the human populations discussed earlier were used to obtain 
TABLE 1. Modern human populations used in the morphometric analysis

\begin{tabular}{lclcc}
\hline \multicolumn{1}{c}{ Population $^{\mathrm{a}}$} & Total & Genetic representative & Centroid size & Average geographic coordinates \\
\hline Alaskan Natives & 20 & None & 106.43 & $68.4 \mathrm{~N}, 166.7 \mathrm{~W}$ \\
Australian Aborigines & 21 & Australians & 94.69 & $34.8 \mathrm{~S}, 138.5 \mathrm{E}$ \\
Hungarians (Medieval) & 21 & French & 98.69 & $46.6 \mathrm{~N}, 18.4 \mathrm{E}$ \\
Khoisan & 19 & San & 98.21 & $20.5 \mathrm{~S}, 19.5 \mathrm{E}$ \\
Malaysians & 21 & Cambodians & 100.23 & $4 \mathrm{~N}, 109.5 \mathrm{E}$ \\
Mongolians & 18 & Mongolians & 103.43 & $46.9 \mathrm{~N}, 103.8 \mathrm{E}$ \\
Native American (Grand Gulch, Utah) & 20 & Pima & 102.91 & $37.6 \mathrm{~N}, 109.8 \mathrm{~W}$ \\
New Guineans & 20 & Papua New Guineans & 97.52 & $6.4 \mathrm{~S}, 150.2 \mathrm{E}$ \\
Nubians (Semna South, Sudanese Nubia) & 43 & Mozabite & 98.63 & $20.0 \mathrm{~N}, 30.1 \mathrm{E}$ \\
Pare (Tanzania) & 19 & Kenyan Bantu & 98.35 & $4.3 \mathrm{~S}, 38.1 \mathrm{E}$ \\
Southern Indians & 21 & None & 94.64 & $13 \mathrm{~N}, 77.56 \mathrm{E}$ \\
Total & 243 & & & \\
\hline
\end{tabular}

a Specimens were housed at Arizona State University (Nubians) or the American Museum of Natural History (all others).

neutral molecular distances. STRs have been shown to be particularly useful and appropriate for determining genetic relationships of populations of Homo sapiens. These loci are autosomal and evolve neutrally such that shared mutations are accepted as evidence of common ancestry. The dataset used here was originally used by Ramachandran et al. (2005) and Rosenberg et al. (2005) and consists of the largest and most inclusive STR dataset published to date. Several of the populations measured in the craniometric study have not been typed for STRs, particularly the archaeological samples (the Nubians and Medieval Hungarians). In these cases, it was necessary to substitute a representative population from the same geographic region and/or linguistic group (Table 1). This practice has been employed in previous studies of the relationship between morphological and molecular distances in modern humans (Relethford, 1994; Roseman, 2004; Harvati and Weaver, 2006a,b). The Alaskan natives and southern India sample had to be omitted from the molecular analysis as neither they nor any other comparable population has been typed for a sufficient number of STR loci. However, these populations were still included in all other analyses in this study.

Approximate geographic coordinates of population origins were estimated using an atlas and published information for the samples. In the case that a range of coordinates was obtained, an average location was used. Data were also compiled on environmental variables in regions from which the populations originated, using data from nearby weather stations (New et al., 1999, 2000) and almanacs. These included rainfall, temperature, altitude, and latitude. The link between these environmental variables and temporal bone morphology could stem directly from local adaptations of cranial shape or indirectly from behaviors mediated by the environment, such as diet or activity levels.

\section{Analytical methods}

The first research question examined the degree to which the morphology of the temporal bone can discriminate among populations of Homo sapiens, and was evaluated in two ways. First, Procrustes distances between groups were calculated, and the significance of these values was assessed via a permutation test (Good, 1993). This form of significance testing compares the observed distance (i.e., test statistic) with a distribution of permuted distances, where individuals are randomly allocated to each group and a mean distance is calculated. A test statistic is considered statistically significant
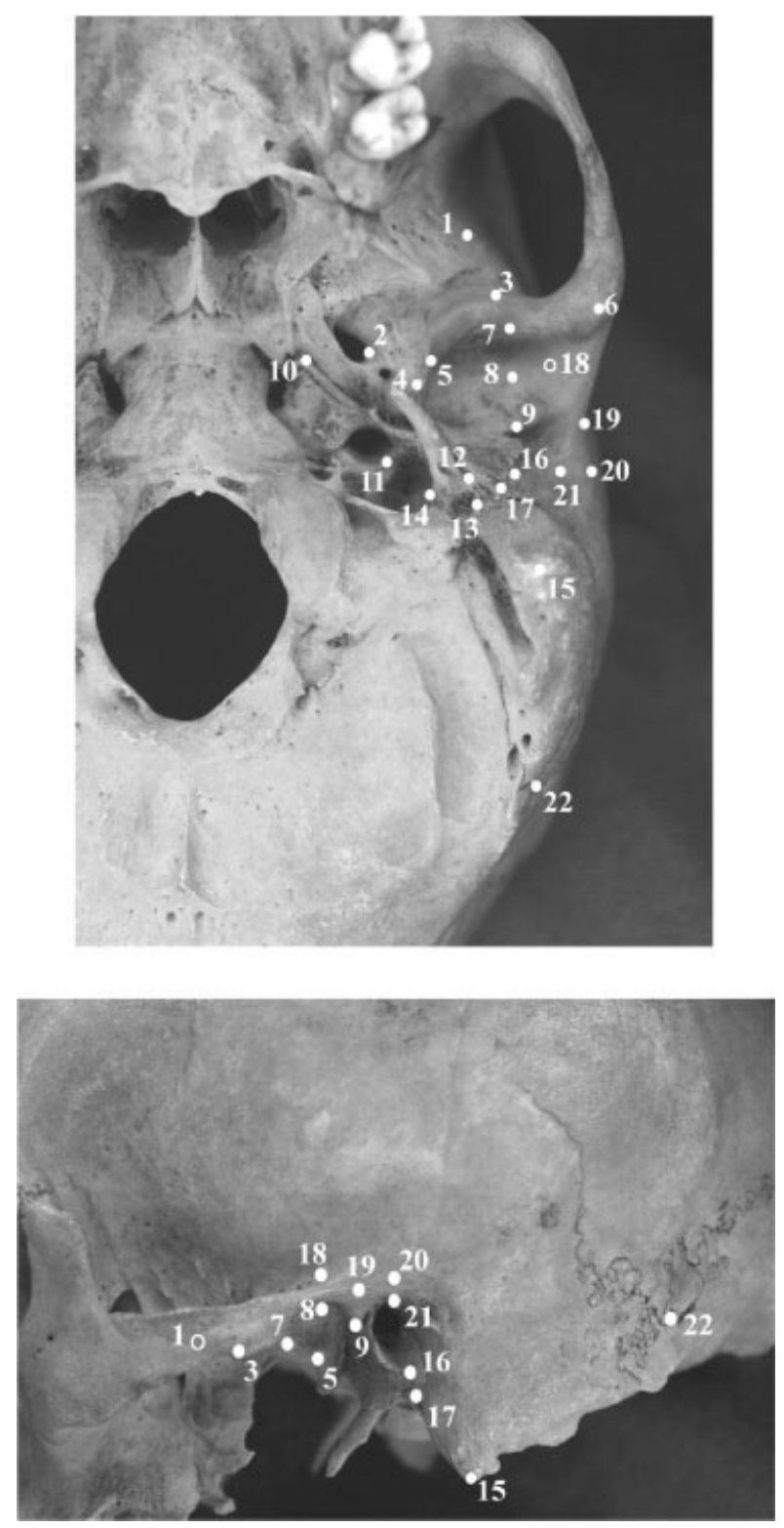

Fig. 2. Twenty-two temporal bone landmarks digitized in the present study (following Lockwood et al., 2002). Refer to Table 2 for landmark definitions. Open circles show the relative positions of landmarks 1 and 18 when these landmarks are not directly visible. 
TABLE 2. Definitions of landmarks used in the present study

\begin{aligned} & \hline No. \\ & \hline 1 Intersection of the infratemporal crest and sphenosquamosal suture \\ & 2 Most lateral point on the margin of foramen ovale \\ & 3 Most anterior point on the articular surface of the articular eminence \\ & 4 Most inferior point on entoglenoid process \\ & 5 Most inferior point on the medial margin of the articular surface of the articular eminence \\ & 6 Midpoint of the lateral margin of the articular surface of the articular eminence \\ & 7 Center of the articular eminence \\ & 8 Deepest point within the mandibular fossa \\ & 9 Most inferior point on the postglenoid process \\ & 10 Anteromedial apex of the petrous part of the temporal bone \\ & 11 Most posterolateral point on the margin of the carotid canal entrance \\ & 12 Most lateral point on the vagina of the styloid process (whether process is present or absent) \\ & 13 Most lateral point on the margin of the stylomastoid foramen \\ & 14 Most lateral point on the jugular fossa \\ & 15 Center of the inferior tip of the mastoid process \\ & 16 Most inferior point on the external acoustic porus \\ & 17 Most inferolateral point on the tympanic element of the temporal bone \\ & 18 Point of inflection where the braincase curves laterally into the supraglenoid gutter, in coronal plane of the mandibular fossa \\ & 19 Point on lateral margin of the zygomatic process of the temporal bone in the coronal plane of the postglenoid process \\ & 20 Auriculare \\ & 21 Porion \\ & 22 Asterion \\ & \hline\end{aligned}

After Lockwood et al. (2002).

$(P$-value $\leq 0.05)$ if it is reached or exceeded in less than $5 \%$ of the random permutations. Second, a discriminant function analysis (DFA) was conducted using the first 40 PC scores from the PCA of Procrustes coordinates (which accounted for $>95 \%$ of variation). The differentiation among populations was then assessed using discriminant analyses with jackknife cross-validation, where prior probabilities were set equal to group size. Since the Nubian sample was significantly larger than all other samples used here $(n=43)$, a reduced sample of 20 randomly chosen individuals was used for this analysis. DFAs were conducted using SPSS (version 11.0.1).

Although Procrustes superimposition scales all specimens to the same unit centroid size, size related shape changes (i.e., allometry) are not removed. Therefore, to assess the role of allometry, a size matrix (i.e., a matrix of the absolute differences in centroid size between groups) was calculated and compared with the Procrustes distance (or shape) matrix using a Mantel test (Mantel, 1976; Smouse et al., 1986) in PopTools, an addon for Microsoft Excel. Additionally, correlations between centroid size and shape were evaluated by regressing the principal component axes on centroid size using Morphologika.

For each analysis, morphological distances (i.e., size or shape distance matrices) were compared to the variable of interest (e.g., molecular or environmental distances). Both Procrustes and Mahalanobis distances were calculated for all populations used here, and these two distance measures were found to be significantly correlated $(r=0.662 ; P<0.001)$. Analyses using both of these distance measures were found to lead to the same general pattern of results. However, while a number of authors (Ackermann, 2002; Strand Viðarsdóttir et al., 2002; Harvati, 2003; Harvati et al., 2004; McNulty, 2005; Harvati and Weaver, 2006a,b) have previously used Mahalanobis distances in analyses such as this, only Procrustes distances are reported here, as Mahalanobis distances attempt to account for within group variation by scaling the values by a pooled within-group covariance matrix, which assumes that all groups in the analysis have similar covariance structures (Ackermann, 2002, 2005; Klingenberg and Monteiro, 2005). This assumption is tenuous given the sample sizes used here. In contrast, since Procrustes distances are not scaled by the pooled within-group covariance matrix, differences in covariance structure between populations should not affect these distances as drastically as they would affect Mahalanobis distances. Also, Mahalanobis distances are affected by uneven sample sizes, while no similar bias has been noted for Procrustes distances.

The second research question addressed the degree of concordance between temporal bone shape and genetic relationships among human populations. This relationship was tested by examining the correlation between matrices of temporal bone morphology (i.e., size and shape matrices) and molecular distances. Analogous studies above the species level have compared phylogenetic trees based on morphology with those based on molecular data (Lockwood et al., 2004; see also Collard and Wood, 2001; Strait and Grine, 2004; Lycett and Collard, 2005). However, within humans, a tree-like structure does not apply to population relationships for morphological or molecular information (summarized by Sherry and Batzer, 1997; Athreya and Glantz, 2003). The current analysis is therefore restricted to matrix correlation comparisons.

STR data were analyzed using Arlequin 3.0 (Excoffier et al., 2005). Data on 783 STRs have been typed for eight representative populations (Ramachandran et al., 2005; Rosenberg et al., 2005), and a subset of 404 of the same STRs has been typed in Native Australians. A matrix of STR population distances was constructed using Slatkin's genetic distance, a distance measure analogous to $\mathrm{F}_{\mathrm{ST}}$ but specifically designed for microsatellite loci in assuming a stepwise mutation model (Slatkin, 1995). The degree and significance of the correlation between the distance matrices from the molecular and morpho- 
TABLE 3. Structure matrix for the discriminant function analysis (first 20 PCs only) showing the correlations between each of the PC axes and discriminant functions

\begin{tabular}{|c|c|c|c|c|c|c|c|c|c|c|}
\hline & \multicolumn{10}{|c|}{ Function } \\
\hline & 1 & 2 & 3 & 4 & 5 & 6 & 7 & 8 & 9 & 10 \\
\hline PC1 & 0.131 & 0.439 & -0.088 & -0.105 & 0.145 & -0.127 & 0.230 & 0.034 & 0.113 & -0.052 \\
\hline PC2 & 0.140 & 0.057 & 0.182 & 0.246 & -0.033 & 0.312 & -0.200 & -0.196 & 0.051 & 0.056 \\
\hline PC3 & 0.076 & -0.211 & -0.061 & 0.063 & 0.327 & -0.118 & 0.071 & 0.122 & -0.124 & -0.169 \\
\hline PC4 & -0.022 & -0.068 & 0.070 & 0.070 & 0.043 & 0.164 & 0.316 & -0.005 & 0.203 & -0.133 \\
\hline PC5 & -0.037 & -0.010 & 0.124 & 0.149 & -0.028 & -0.381 & 0.102 & 0.037 & -0.052 & 0.309 \\
\hline PC6 & 0.189 & 0.018 & -0.238 & 0.379 & -0.051 & -0.153 & 0.031 & 0.094 & -0.113 & 0.144 \\
\hline PC7 & -0.069 & 0.228 & -0.073 & 0.186 & 0.142 & 0.152 & -0.062 & 0.165 & -0.357 & -0.068 \\
\hline PC8 & 0.029 & 0.022 & 0.141 & -0.136 & 0.193 & 0.037 & -0.049 & -0.069 & -0.033 & -0.093 \\
\hline PC9 & 0.138 & -0.055 & 0.013 & 0.060 & 0.172 & 0.014 & 0.175 & -0.137 & 0.023 & 0.009 \\
\hline PC10 & -0.173 & 0.079 & 0.029 & 0.287 & 0.133 & -0.005 & 0.149 & 0.038 & 0.223 & 0.018 \\
\hline PC11 & 0.053 & 0.035 & 0.149 & -0.091 & 0.043 & 0.060 & 0.130 & 0.165 & -0.094 & 0.286 \\
\hline PC12 & 0.012 & 0.037 & 0.037 & 0.006 & 0.059 & -0.080 & -0.049 & 0.141 & 0.087 & 0.164 \\
\hline PC13 & 0.061 & -0.028 & -0.039 & -0.140 & -0.066 & 0.156 & -0.135 & 0.445 & -0.081 & -0.062 \\
\hline PC14 & 0.102 & -0.094 & 0.208 & 0.224 & -0.125 & -0.022 & -0.050 & 0.064 & -0.056 & -0.244 \\
\hline PC15 & -0.105 & 0.015 & 0.192 & 0.121 & 0.023 & -0.035 & -0.044 & 0.042 & 0.071 & 0.053 \\
\hline PC16 & 0.020 & -0.030 & 0.084 & -0.046 & 0.010 & 0.211 & 0.206 & 0.012 & -0.065 & 0.242 \\
\hline PC17 & -0.019 & 0.085 & 0.032 & 0.023 & 0.127 & 0.072 & -0.143 & 0.225 & 0.390 & -0.093 \\
\hline PC18 & -0.011 & -0.098 & 0.015 & -0.037 & 0.182 & 0.123 & -0.142 & 0.025 & 0.029 & 0.250 \\
\hline PC19 & 0.010 & -0.033 & 0.196 & -0.001 & 0.110 & -0.092 & -0.070 & 0.210 & -0.034 & -0.096 \\
\hline PC20 & -0.049 & -0.073 & -0.018 & 0.037 & 0.150 & 0.015 & 0.086 & -0.276 & -0.129 & 0.064 \\
\hline
\end{tabular}

logical analyses was assessed using a Mantel test, again in PopTools.

Finally, environmental variables and geographic distances for populations were evaluated to determine how they covary with temporal bone morphology. Environmental distance matrices were generated for each environmental variable: temperature, rainfall, latitude, and altitude. A single overall environmental distance matrix (Euclidean distance, incorporating data from all four environmental variables) was also calculated in PopTools. To address the possibility that environmental factors influenced morphological difference, the morphological distance matrices were compared to each environmental matrix using a Mantel test.

To test the association between geography and morphology, geographic great circle distances among populations were calculated. Great circle distances use latitude and longitude and take into account the fact that these coordinates are on the circumference of a sphere to calculate distances between two locations. A geographic matrix was generated using great circle distances and including five waypoints (Fig. 1), geographic locations through which populations would have had to travel when migrating between two continents (Relethford, 2004; Ramachandran et al., 2005). This practice takes into account the conclusion that most human migrations, until recently, did not usually traverse large bodies of water (Ramachandran et al., 2005). The inclusion of waypoints, therefore, permits a more accurate estimate of the migrational distance among populations, rather than a line of minimal geographic distance that could run across an ocean. The pairwise distance between any two populations was calculated as the sum of the distance between Population 1 and the waypoint, and between the waypoint and Population 2, plus any distances between waypoints if more than one waypoint fell between the populations. Following Ramachandran et al. (2005), waypoints included were Anadyr, Russia; Cairo, Egypt; Istanbul, Turkey; Phnom Penh, Cambodia; and Prince Rupert, Canada. Geographic distances among populations on the same continent were calculated as normal great circle distances. It is probable even within
TABLE 4. Eigenvalues, distribution of variance, and canonical correlations for the discriminant function analysis

\begin{tabular}{ccccc}
\hline Function & Eigenvalue & $\begin{array}{c}\% \text { of } \\
\text { variance }\end{array}$ & $\begin{array}{c}\text { Cumulative } \% \\
\text { correlation }\end{array}$ \\
\hline 1 & 6.39 & 40.81 & 40.81 & 0.93 \\
2 & 2.78 & 17.75 & 58.56 & 0.86 \\
3 & 1.44 & 9.18 & 67.74 & 0.77 \\
4 & 1.29 & 8.23 & 75.97 & 0.75 \\
5 & 1.21 & 7.74 & 83.71 & 0.74 \\
6 & 0.91 & 5.82 & 89.53 & 0.69 \\
7 & 0.58 & 3.69 & 93.22 & 0.61 \\
8 & 0.45 & 2.87 & 96.09 & 0.56 \\
9 & 0.33 & 2.11 & 98.20 & 0.50 \\
10 & 0.28 & 1.80 & 100.00 & 0.47 \\
\hline
\end{tabular}

continents that migrational distances are affected by geographical barriers and are not simply great circle distances; this factor is considered later in discussing the results. The hypothesis that temporal bone morphology covaries with geographic distance was then assessed by comparing the geographic matrix with the morphological matrix using a Mantel test.

For all analyses, alpha was set at 0.05 . All correlations are reported as Pearson product moment correlation coefficients $(r)$.

\section{RESULTS}

In the DFA, the first function is influenced by a variety of principal components and accounts for just over $40 \%$ of variance among populations (Tables 3 and 4 ). As expected, contributions of subsequent functions diminish rapidly (Table 4 ).

Permutation tests of the Procrustes distances among populations were all statistically significant with $P$-values of less than 0.001 (Table 5). The DFA with crossvalidation demonstrates that the populations can be distinguished relatively well, with classification rates between 56 and $85 \%$ (mean $73 \%$ ) (Table 6). For 11 populations of roughly equal sample size, the expected proportion of correct random classifications is $\sim 9 \%$, so these results indicate high success rates. 
TEMPORAL BONE VARIATION IN MODERN HUMANS
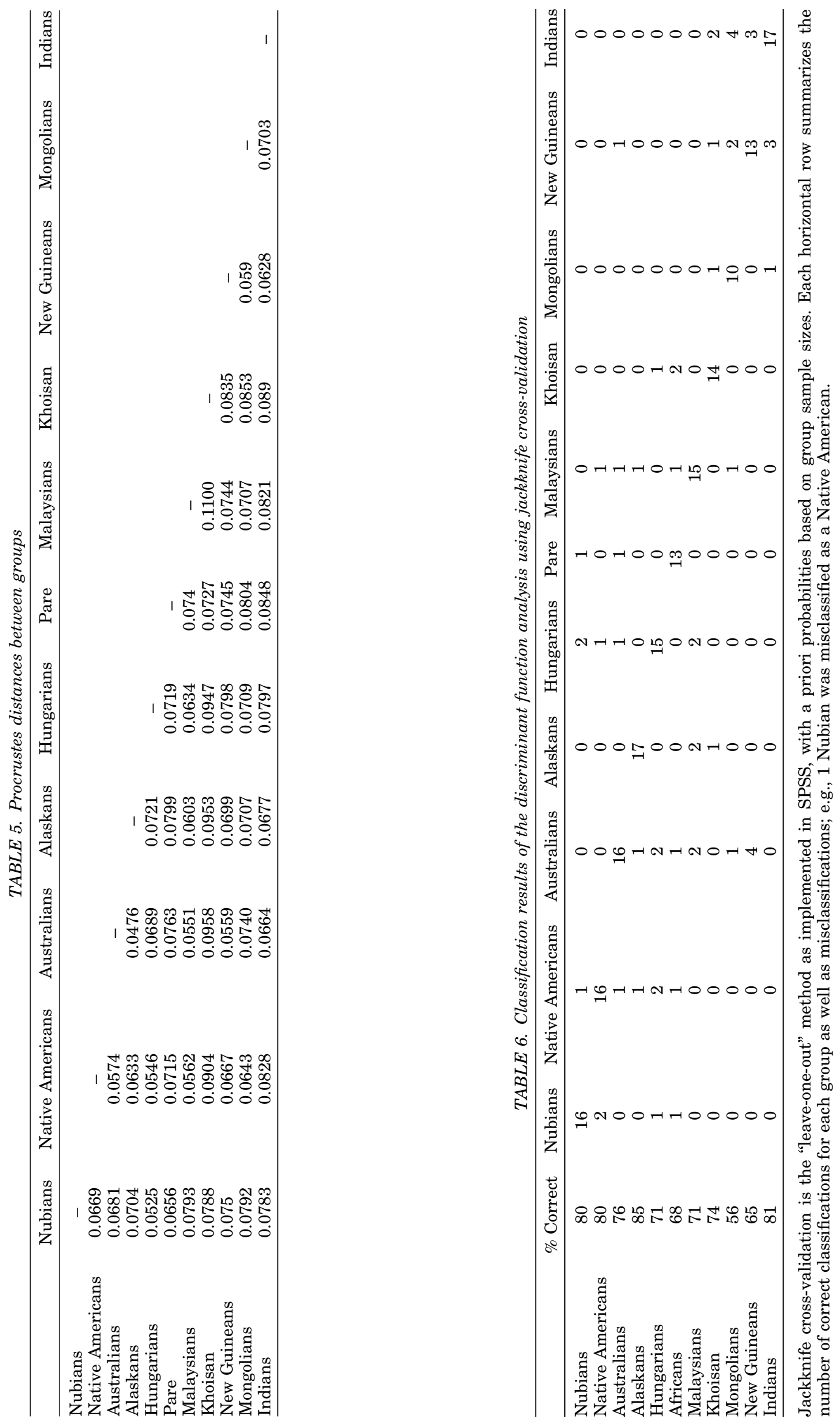
TABLE 8. Results of the Mantel tests performed between morphological matrices (shape and size) and the molecular, geographic, and environmental matrices

\begin{tabular}{llllll}
\hline & \multicolumn{2}{c}{ Shape } & & \multicolumn{2}{c}{ Size } \\
\cline { 2 - 3 } \cline { 5 - 6 } & \multicolumn{1}{c}{$r$} & $P$ & & $r$ & $P$ \\
\hline Molecular distance & 0.205 & 0.175 & & 0.298 & 0.15 \\
Molecular without & $0.629^{\mathrm{a}}$ & 0.003 & & -0.032 & 0.469 \\
$\quad$ Utah Native Americans & & & & & \\
Geography & 0.221 & 0.095 & & 0.233 & 0.11 \\
Geography without & $0.338^{\mathrm{a}}$ & 0.029 & & 0.179 & 0.157 \\
$\quad$ Utah Native Americans & & & & \\
Temperature & -0.144 & 0.208 & & $0.713^{\mathrm{a}}$ & 0.001 \\
Rainfall & -0.045 & 0.516 & & -0.114 & 0.415 \\
Latitude & -0.129 & 0.195 & & $0.420^{\mathrm{a}}$ & 0.021 \\
Altitude & -0.05 & 0.419 & -0.028 & 0.499 \\
Combined environment & -0.106 & 0.293 & & -0.103 & 0.327 \\
\hline
\end{tabular}

$r=$ Pearson correlation coefficients.

a Correlations significant at $P<0.05$.

Allometric affects within the sample were assessed using a Mantel test of the correlation between the Procrustes distance shape matrix (Table 5) and the size matrix (Table 7). Results of this analysis indicate that the size and shape matrices are uncorrelated $(r=-0.123$, $P=0.28$ ). Additionally, regression of the first 30 principal components (which account for $\sim 90 \%$ of the sample variance) on centroid size indicated that, although a number of these PCs are significantly correlated with size, the $R^{2}$ values for these correlation are very low (i.e., $R^{2}<0.04$ ), with the exception of PC 4 , where $R^{2}=$ 0.172 and the $P$-value was highly statistically significant $(P<0.00001)$. These results suggest that while there may be some allometric affects within the sample as a whole, morphological differentiation between populations is not primarily a result of allometry.

Mantel tests for morphological, molecular, geographic, and environmental differences are summarized in Table 8. Results for the comparison of morphological and molecular distance are substantially different depending on whether the Utah Native American sample is included. When it is included along with all other populations, the correlation between molecular distances (Table 9) and temporal bone morphology was not statistically significant (molecular distance vs. shape: $r=0.205, P=0.175$; molecular distance $v s$. size: $r=0.298, P=0.15$ ). Excluding the Native American sample, the correlation between the Procrustes distance and molecular distance was strongly significant $(r=0.629, P=0.003)$, although the centroid size and molecular distance matrices remained uncorrelated $(r=-0.032, P=0.469$ ).

In explaining this result, we note that the molecular distances between the Native Americans and all other populations were extremely high (Table 9); in some cases, the molecular distance between the Native American group and others was an order of magnitude greater than distances observed between other populations. At least according to the STR data, neutral genetic distances are not distributed in a way that facilitates comparison to morphological distances in this group. Therefore, the analysis excluding Native Americans is probably more representative of the true pattern of relationships.

No significant correlation was found between the temporal bone shape matrix and any of the environmental matrices. There was also no significant correlation between the size matrix and the environmental variables of altitude, rainfall, or the combined environmental 
TABLE 9. Molecular distance matrix

\begin{tabular}{lcccccccc}
\hline & & & & & New & $\begin{array}{c}\text { Son } \\
\text { Guineans }\end{array}$ Mongolians \\
\hline Mozabite & - & & & & & & & \\
Pima & $\mathbf{0 . 1 3 0 9 7}$ & - & & & & & & \\
Australians & 0.05873 & $\mathbf{0 . 1 5 7 0 5}$ & - & & & & \\
French & 0.01643 & $\mathbf{0 . 1 1 7 3 5}$ & 0.05430 & - & & & - \\
Kenyan Bantu & 0.03332 & $\mathbf{0 . 1 5 8 5 3}$ & 0.07665 & 0.04588 & - & & \\
Cambodians & 0.04064 & $\mathbf{0 . 1 0 7 7 8}$ & 0.05266 & 0.03697 & 0.06628 & & \\
San & 0.07455 & $\mathbf{0 . 2 0 8 4 5}$ & 0.11348 & 0.08725 & 0.05328 & 0.09976 & 0.12706 & - \\
New Guineans & 0.07951 & $\mathbf{0 . 1 5 4 0 5}$ & 0.06320 & 0.07234 & 0.08941 & 0.07179 & 0.07021 \\
Mongolians & 0.04371 & $\mathbf{0 . 0 9 8 3 8}$ & 0.05739 & 0.03417 & 0.06230 & 0.00487 & 0.09888 & - \\
\hline
\end{tabular}

These values were calculated using Slatkin's genetic distance for microsatellites (Slatkin, 1995). Note the high values of molecular distances between the Native American population (Pima) and all other populations, as indicated in bold.

matrix. However, a significant positive correlation was found between size and temperature $(r=0.713, P=$ $0.001)$, and size and latitude $(r=0.420, P=0.021)$. Since Harvati and Weaver (2006b) found that the correlation between size and climate was only obtained if their specifically cold-adapted population was included in the analysis, the Alaskan population was removed from the comparisons of size to temperature and latitude. The rationale for removing this population is to determine whether there is a general pattern of correlation among all populations, or whether it is primarily a single cold-adapted population driving the correlation. For temperature, although the correlation with centroid size dropped to $r=0.569$, it remained significant $(P=$ 0.01 ). For latitude, the correlation with size dropped to a nonsignificant correlation of $r=0.07$.

The correlation between geographic distance (Table 10) and morphological distance for all 11 populations was not significant (geography $v s$. shape: $r=0.221, P=$ 0.095 ; geography $v s$. size: $r=0.233, P=0.11$ ). However removal of the Utah Native American group from the analysis resulted in a significant correlation between geographic distance and morphology $(r=0.338, P=$ 0.029). The STRs used in this study were found to show a significant correlation with geographic distances $(r=$ $0.779, P<0.001)$.

\section{DISCUSSION}

Although the shape of the temporal bone has long been used in analyses of population affinities and species relationships, the degree to which it reflects neutral genetic evolution has not been fully addressed, and the nature of the environmental influence on this element is unclear. Our goal was therefore to explore the relationship between temporal bone morphology and genetic, environmental, and geographic variation. Three hypotheses were tested, and the results suggest that: 1) there are significant differences in temporal bone morphology among modern human populations; 2) shape (but not size) differences partially reflect neutral evolution; 3) geographic distance is a significant factor but plays a smaller role in shape variation; 4) shape of the temporal bone is not significantly associated with climate, altitude, or temperature, and 5) size of the temporal bone is significantly correlated with temperature and latitude.

\section{Temporal bone morphology, group affiliation, and genetic differentiation}

Our analysis shows that the temporal bone has high discriminatory power for human populations even when analyzed on its own. This result is consistent with similar studies on humans and other taxa (Harvati, 2003; Lockwood et al., 2002; Lockwood et al., 2004), and it provides an important comparison for previous analyses that have used the temporal bone to discriminate between species and subspecies of great apes and fossil hominins (Harvati, 2003; Harvati et al., 2004; Lockwood et al., 2004; Terhune et al., 2007).

Although it initially appeared that the correlation between molecular distance and morphological distance based on the temporal bone was not significant, removal of the Utah Native American population increased the correlation substantially. This finding may indicate that the modern genetic analogue, the Pima, was not representative of the older morphological sample from Grand Gulch, Utah. Alternatively, the marked genetic differentiation of the Pima sample may be the result of the extreme bottle-necking hypothesized to have occurred during the migration of early Americans to the New World (Szathmary, 1993; Santos et al., 1995; Monsalve et al., 1999; Bortolini et al., 2002; Battilana et al., 2006). While neutral molecular markers may drift unchecked, the cranium is likely to be under some degree of stabilizing selection. A bottle-neck event may explain why the molecular distance of the Native Americans is high relative to other populations and perhaps exaggerated, while their morphology is broadly similar to other groups. In any case, our results without Native American samples are similar to those of Harvati and Weaver (2006a,b), who also did not include a native North American sample in their genetic analysis.

Overall, the correlation between molecular and morphological distance of the temporal bone was relatively good. The finding that the morphology of the temporal bone reflects genetic relationships among human populations is consistent with studies that have identified an association between other aspects of cranial morphology and genetic relationships in humans (Relethford, 2001, 2002; Gonzales-Jose et al., 2004; Roseman, 2004). These results are also consistent with those of Harvati and Weaver $(2006 \mathrm{a}, \mathrm{b})$, who found a significant correlation between molecular and morphological distances using different populations and different temporal bone landmarks from this study. The temporal bone contains information about genetic relationships within humans, as it does among hominoid species, and it may therefore serve as a reliable means of assessing relationships when molecular data are unavailable. However, in addition to the difficulty in explaining low morphological distances between Native Americans and other groups, the molecular distance matrix among Old World populations 
explains only $\sim 39 \%$ of morphological variation in the temporal bone. Clearly, other factors play a substantial role in temporal bone morphology in humans.

\section{Geographic distance}

There is also a general association between morphological and geographic distances. Together with the genetic correlation, this finding indicates that the temporal bone is evolving to some degree under an "isolation by distance" model (Wright, 1943; Morton et al., 1971; CavalliSforza et al., 1994), which predicts that variation increases with geographic distance among populations. The relationship of geographic distance, neutral genetic distance, and temporal bone morphology points to the neutral component of temporal bone variation.

As with the molecular distance analysis, the correlation between morphological and geographic distance was only significant if the Utah Native American population was removed from the analysis. This group had the highest average geographic distance from all other populations, but its morphological distances to other groups were not particularly high. This pattern may reflect the recent arrival of humans into the Americas. Also, there may be a threshold beyond which additional geographic distance does not translate into additional morphological distance, especially if stabilizing selection restricts the potential variation in temporal bone morphology. Along similar lines, the Utah Native American group may share morphology with distant populations due to aspects of ecology not studied here.

\section{Environment}

None of the environmental variables included in this study (altitude, latitude, rainfall, and temperature) showed a significant correlation with temporal bone shape. These findings are consistent with those of Harvati and Weaver (2006a,b), who found that temporal bone shape was not significantly associated with humidity, latitude, or temperature (they did not look at rainfall). Temporal bone size, however, was found to covary with temperature and latitude, largely because of the inclusion of a sample from Alaska. These environmental variables are not entirely separate entities, as the temperature and latitude matrices were found to be highly correlated with each other $(r=0.855, P<0.001)$. Thus, it seems likely that temperature is the predominant environmental influence over human temporal bone size, as would be predicted by Bergmann's Rule (Bergmann, 1847), and that the correlation with latitude is simply a by-product of that effect. Harvati and Weaver (2006a,b) also found temporal bone size to be correlated with temperature. As one might expect, the size of the temporal bone is probably less informative than temporal bone shape for inferring genetic affinities between populations.

Although temporal bone shape correlates with genetic and geographic distance between populations, a relatively large proportion of human temporal bone variation remains unexplained by the factors investigated here. Some of this variation may be related to variation in the shape of the cranial component of the TMJ, the morphology of which is described by the landmarks included in this study. Within primates, some aspects of TMJ shape have been linked to variation in masticatory function, and specifically to food material properties and dental function (Bouvier, 1986a,b; Wall, 1999; Vinyard et al., 
2003). Therefore, the material properties of foods utilized by the populations sampled in this study may be a significant factor in the observed morphological variation. Further analysis should focus directly on diet in an effort to partition the effects of different environmental factors and to obtain more direct indicators of the environmental component of human temporal bone shape.

\section{CONCLUSIONS}

Based on geometric morphometric analysis and DFA, the present study found that modern human populations can be distinguished from one another on the basis of their temporal bone shape, and classification rates (cross-validated) are relatively high for the 11 populations studied here. Differences among populations in temporal bone shape are correlated with geographic and neutral molecular distances, pointing to a small but significant neutral component of temporal bone variation that may reflect an isolation by distance model of population differentiation. These results confirm the findings of Harvati and Weaver (2006a,b) and are consistent with the use of temporal bone shape to study population affinities. However, our conclusions are tempered by the absence of significant correlations with geographic distance when a native North American samples is included, and by unusually high molecular distances from this population to other human groups.

Although significant, the correlations between temporal bone shape and molecular and geographic distances also show that much of the observed variation in temporal bone morphology can be explained by other factors. Temporal bone shape does not correlate strongly with the environmental variables included here (rainfall, temperature, latitude, and altitude). The main environmental effect is seen between temporal bone size and temperature and latitude. Thus, further work, particularly on dietary effects, is necessary to resolve other factors involved in temporal bone shape. Although the temporal bone is only one element of the skull, this study shows the potential information available when morphological details of skull shape are quantified, as well as the utility of this element when preserved in isolation in the fossil record.

\section{ACKNOWLEDGMENTS}

Special thanks go to Katerina Harvati and Timothy Weaver for sharing their book chapter with us while it was still in press. We are grateful to Ian Tattersall and Gary Sawyer of the American Museum of Natural History and Diane Hawkey of Arizona State University for permission to study collections in their care. This manuscript was greatly improved by comments from Mark Spencer, Katerina Harvati, the editor Clark Larsen, and one anonymous reviewer.

\section{LITERATURE CITED}

Ackermann RR. 2002. Patterns of covariation in the hominoid craniofacial skeleton: implications for paleoanthropological models. J Hum Evol 42:167-187.

Ackermann RR. 2005. Variation in Neandertals: a response to Harvati (2003). J Hum Evol 48:643-646.

Asfaw B, White T, Lovejoy O, Latimer B, Simpson S, Suwa G. 1999. Australopithecus garhi: a new species of hominid from Ethiopia. Science 284:629-635.
Athreya S, Glantz MM. 2003. The impact of character correlation and variable groupings on modern human population tree resolution. Am J Phys Anthropol 122:134-146.

Battilana J, Fagundes NJ, Heller AH, Goldani A, Freitas LB, Tarazona-Santos E, Munkhbat B, Munkhtuvshin N, Krylov M, Benevolenskaia L, Arnett FC, Batzer MA, Deininger PL, Salzano FM, Bonatto SL. 2006. Alu insertion polymorphisms in Native Americans and related Asian populations. Ann Hum Biol 33:142-160.

Bergmann C. 1847. Ueber die Verhaltnisse de Wärmeökonomie des Thieres zu ihrer Grösse. Gottinger Stud 3:595-708.

Bortolini MC, Salzano FM, Bau CH, Layrisse Z, Petzl-Erler ML, Tsuneto LT, Hill K, Hurtado AM, Castro-De-Guerra D, Bedoya G, Ruiz-Linares A. 2002. Y-chromosome biallelic polymorphisms and Native American population structure. Ann Hum Genet 66:255-259.

Bouvier M. 1986a. A biomechanical analysis of mandibular scaling in Old World monkeys. Am J Phys Anthropol 69:473482.

Bouvier M. 1986b. Biomechanical scaling of mandibular dimensions in New World monkeys. Int J Primatol 7:551-567.

Carey JW, Steegman AT. 1981. Human nasal protrusion, latitude, and climate. Am J Phys Anthropol 56:313-319.

Cavalli-Sforza LL, Menozzi P, Piazza A. 1994. The history and geography of human genes. Princeton, NJ: Princeton University Press.

Collard M, Wood B. 2001. Homoplasy and the early hominid masticatory system: inferences from analyses of extant hominoids and papionins. J Hum Evol 41:167-194.

Dryden IL, Mardia KV. 1998. Statistical shape analysis. London: Wiley.

Excoffier L, Laval G, Schneider S. 2005. Arlequin ver. 3.0: an integrated software package for population genetics data analysis. Evol Bioinform Online 1:47-50.

Franciscus RG, Long JC. 1991. Variation in human nasal height and breadth. Am J Phys Anthropol 85:419-427.

Gonzales-Jose R, Van der Molen S, Gonzales-Perez E, Hernandez M. 2004. Patterns of phenotypic covariation and correlation in modern humans as viewed from morphological integration. Am J Phys Anthropol 123:69-77.

Goodall CR. 1991. Procrustes methods and the statistical analysis of shape (with discussion). Proc R Soc Lond B Biol Sci 53:285-340.

Good P. 1993. Permutation tests: a practical guide to resampling methods for testing hypotheses. New York: Springer-Verlag.

Gower JC. 1975. Generalised procrustes analysis. Psychometrika 40:33-50.

Harvati K. 2001. The Neanderthal problem: 3-D geometric morphometric models of cranial shape variation within and among species. Ph.D. dissertation, City University of New York.

Harvati K. 2003. Quantitative analysis of Neanderthal temporal bone morphology using three-dimensional geometric morphometrics. Am J Phys Anthropol 120:323-338.

Harvati K, Frost SR, McNulty KP. 2004. Neanderthal taxonomy reconsidered: implications of 3D primate models of intra- and interspecific differences. Proc Natl Acad Sci USA 101:11471152.

Harvati K, Weaver TD. 2006a. Reliability of cranial morphology in reconstructing Neandertal phylogeny. In: Harrison T, Harvati $\mathrm{K}$, editors. Neandertals revisited: new approaches and perspectives. Dordrecht: Springer. p 239-254.

Harvati K, Weaver TD. 2006b. Human cranial anatomy and the differential preservation of population history and climate signatures. Anat Rec A 288:1225-1233.

Houghton P. 1996. The people of the great ocean: aspects of human biology in the early Pacific. New York: Cambridge University Press.

Klingenberg CP, Monteiro LR. 2005. Distances and directions in multidimensional shape spaces: implications for morphometric applications. Syst Biol 54:678-688.

Lieberman DE, Ross CF, Ravosa MJ. 2000a. The primate cranial base: ontogeny, function, and integration. Yrbk Phys Anthropol 43:117-169. 
Lieberman DE, Pearson OM, Mowbray KM. 2000b. Basicranial influence on overall cranial shape. J Hum Evol 38:291-315.

Lieberman DE, Wood BA, Pilbeam DR. 1996. Homoplasy and early Homo: an analysis of the evolutionary relationships of $H$. habilis sensu stricto and $H$. rudolfensis. J Hum Evol 30:97-120.

Lockwood CA, Kimbel WH, Lynch JM. 2004. Morphometrics and hominoid phylogeny: support for a chimpanzee-human clade and differentiation among great ape species. Proc Natl Acad Sci USA 101:4356-4360.

Lockwood CA, Kimbel WH, Lynch JM. 2005. Variation in early hominin temporal bone morphology and its implications for species diversity. Trans R Soc South Africa 60:73-77.

Lockwood CA, Lynch JM, Kimbel WH. 2002. Quantifying temporal bone morphology of great apes and humans: an approach using geometric morphometrics. J Anat 201:447-464.

Lycett SJ, Collard M. 2005. Do homoiologies impede phylogenetic analyses of the fossil hominids? An assessment based on extant papionin craniodental morphology. J Hum Evol 49: 618-642.

MacPhee RDE, Cartmill M. 1986. Basicranial structures and primate systematics. In: Swindler DR, Erwin J, editors. Comparative primate biology, Vol. 1: systematics, evolution, and anatomy. New York: Liss. p 219-275.

Mantel N. 1967. The detection of disease clustering and a generalized regression approach. Cancer Res 27:209-220.

Martinez I, Arsuaga JL. 1997. The temporal bones from Sima de los Huesos Middle Pleistocene site (Sierra de Atapuerca, Spain). A phylogenetic approach. J Hum Evol 33:283-318.

McHenry HM. 1994. Tempo and mode of human evolution. Proc Natl Acad Sci USA 91:6780-6786.

McHenry HM. 1996. Homoplasy, clades and hominid phylogeny. In: Meikle WE, Howell FC, Jablonski NG, editors. Contemporary issues in human evolution. San Francisco: California Academy of Sciences. p 77-92.

McNulty KP. 2005. A geometric morphometric assessment of the hominoids supraorbital region: affinities of the Eurasian Miocene hominoids Dryopithecus, Graecopithecus, and Sivapithecus. In: Slice D, editor. Modern morphometrics in physical anthropology. New York: Kluwer Academic/Plenum. p 349-371.

Monsalve MV, Helgason A, Devine DV. 1999. Languages, geography and HLA haplotypes in native American and Asian populations. Proc Biol Sci 266:2209-2216.

Moore WJ, Lavelle CJB. 1974. Growth of the facial skeleton in the Hominoidea. London: Academic Press.

Morton NE, Yee S, Harris DE, Lew R. 1971. Bioassay of kinship. Theor Popul Biol 2:507-524.

Moss ML. 1962. The functional matrix. In: Kraus B, Riedel R, editors. Vistas in orthodontics. Philadelphia: Lea \& Febiger. $p$ 85-98.

Moss ML. 1972. Twenty years of functional cranial analysis. Am J Orthod 61:479-485.

New M, Hulme M, Jones P. 1999. Representing twentieth-century space-time climate variability. I. Development of a 196190 mean monthly terrestrial climatology. J Clim 12:829-856.

New M, Hulme M, Jones P. 2000. Representing twentieth-century space-time climate variability. II. Development of 196190 monthly grids of terrestrial surface climate. J Clim 13:2217-2238.

O'Higgins P, Jones N. 1998. Facial growth in Cercocebus torquatus: an application of three-dimensional geometric morphometric techniques to the study of morphological variation. J Anat 193:251-272.

Olson TR. 1981. Basicranial morphology of the extant hominoids and Pliocene hominids: the new material from the Hadar Formation, Ethiopia and its significance in early human evolution and taxonomy. In: Stringer CB, editor. Aspects of human evolution. London: Taylor and Francis. p 99-128.

Ramachandran S, Deshpande O, Roseman CC, Rosenberg NA, Feldman MW, Cavalli-Sforza LL. 2005. Support from the rela- tionships of genetic and geographic distance in human populations for a serial founding effect originating in Africa. Proc Natl Acad Sci USA 102:15942-15947.

Relethford JH. 1994. Craniometric variation among modern human populations. Am J Phys Anthropol 95:53-62.

Relethford JH. 1998. Mitochondrial DNA and ancient population growth. Am J Phys Anthropol 105:1-7.

Relethford JH. 2001. Global analysis of regional differences in craniometric diversity and population substructure. Hum Biol 73:629-636.

Relethford JH. 2002. Apportionment of global human genetic diversity based on craniometrics and skin color. Am J Phys Anthropol 118:393-398.

Relethford JH. 2004. Global patterns of isolation by distance based on genetic and morphological data. Hum Biol 76:499513.

Roseman CC. 2004. Detecting interregionally diversifying natural selection on modern human cranial form by using matched molecular and morphometric data. Proc Natl Acad Sci USA 101:12825-12829.

Rosenberg NA, Mahajan S, Ramachandran S, Zhao C, Pritchard JK, Feldman MW. 2005. Clines, clusters, and the effect of study design on the inference of human population structure. PLoS Genet 1:660-671.

Santos FR, Hutz M, Coimbra CEA, Santos RV, Salzano FM, Pena SDJ. 1995. Further evidence for the existence of a major founder $\mathrm{Y}$ chromosome haplotype in Amerindians. Braz J Genet 18:669-672.

Sherry ST, Batzer MA. 1997. Modeling human evolution-to tree or not to tree. Genome Res 7:947-949.

Skelton R, McHenry M. 1992. Evolutionary relationships among early hominids. J Hum Evol 23:309-349.

Slatkin M. 1995. A measure of population subdivision based on microsatellite allele frequencies. Genetics 139:457-462.

Smouse PE, Long JC, Sokal RT. 1986. Multiple regression and correlation extensions of the Mantel test of matrix correspondence. Syst Zool 35:627-632.

Strait DS, Grine FE, Moniz MA. 1997. A reappraisal of early hominid phylogeny. J Hum Evol 32:17-82.

Strait DS, Grine FE. 2004. Inferring hominoid and early hominid phylogeny using craniodental characters: the role of fossil taxa. J Hum Evol 47:399-452.

Strand Viðarsdóttir U, O’Higgins P, Stringer C. 2002. A geometric morphometric study of regional differences in the ontogeny of the modern human facial skeleton. J Anat 201:211-229.

Szathmary EJE. 1993. Genetics of aboriginal North Americans. Evol Anthropol 1:202-220.

Terhune CE, Kimbel WH, Lockwood CA. 2007. Variation and diversity in Homo erectus: a 3-D geometric morphometric analysis of the temporal bone. J Hum Evol. doi:10.1016/j.jhevol. 2007.01.006.

Turner A, Wood BA. 1993. Comparative palaeontological context for the evolution of the early hominid masticatory system. J Hum Evol 24:301-318.

Vinyard CJ, Wall CE, Williams SH, Hylander WL. 2003. Comparative functional analysis of skull morphology of tree-gouging primates. Am J Phys Anthropol 120:153-170.

Walker A, Leakey RE, Harris JM, Brown FH. 1986. 2.5-Myr Australopithecus boisei from west of Lake Turkana, Kenya. Nature 322:517-522.

Wall CE. 1999. A model of temporomandibular joint function in anthropoid primates based on condylar movements during mastication. Am J Phys Anthropol 109:67-88.

Wood BA. 1988. Are the 'robust' australopithecines a monophyletic group? In: Grine FE, editor. Evolutionary history of the "robust" australopithecines. New York: Aldine de Gruyter. p 269-284.

Wood B, Lieberman DE. 2001. Craniodental variation in Paranthropus boisei: a developmental and functional perspective. Am J Phys Anthropol 116:13-25.

Wright S. 1943. Isolation by distance. Genetics 28:114-138. 